\title{
On the Contrary: Inferential Analysis and Ontological Assumptions of the A Contrario Argument*
}

\author{
DAMIANO CANALE \\ GIOVANNI TUZET
}

\author{
IDC - Institute of Comparative Law \\ Bocconi University \\ Via Gobbi, 5 \\ 20136 Milan \\ Italy \\ damiano.canale@unibocconi.it \\ giovanni.tuzet@unibocconi.it
}

\begin{abstract}
We remark that the $A$ Contrario Argument is an ambiguous technique of justification of judicial decisions. We distinguish two uses and versions of it, strong and weak, taking as example the normative sentence "Underprivileged citizens are permitted to apply for State benefit”. According to the strong version, only underprivileged citizens are permitted to apply for State benefit, so stateless persons are not. According to the weak, the law does not regulate the position of underprivileged stateless persons in this respect. We propose an inferential analysis of the two uses along the lines of the scorekeeping practice as described by Robert Brandom, and try to point out what are the ontological assumptions of the two. We conclude that the strong version is justified if and only if there is a relevant incompatibility between the regulated subject and the present case.
\end{abstract}

Résumé: Nous faisons remarquer que l'argument a contrario est une technique ambiguë de justification de décisions judiciaires. Nous employons la phrase, « Les citoyens défavorisés sont permis de faire une demande d'aide gouvernementale », pour illustrer deux usages et deux versions de cet argument: fortes et faibles. Selon la version forte, seulement des citoyens défavorisés sont permis de faire une telle demande, donc des personnes qui ne sont pas citoyens n'y sont pas permises. Selon la version faible, la loi ne gère pas de cette façon les personnes défavorisées qui ne sont pas citoyens. Nous proposons une analyse inférentielle de ces deux usages qui est influencée par la pratique, décrite par Robert Brandon, de marquer des points dans les sports, et tentons d'exposer les suppositions ontologiques de ces deux usages. Nous concluons que la version forte est justifiée si et seulement s’il y a une incompatibilité pertinente entre le sujet gouverné et le cas présent.

Keywords: A Contrario argument, exchange of reasons, gaps in the law, incompatibility relations, inferentialism, legal argumentation, legal reasoning, negation, ontological assumptions.

* This paper elaborates on our previous paper "The A Contrario Argument: A Scorekeeping Model”, in the Proceedings of the Sixth Conference of the International Society for the Study of Argumentation (Amsterdam: SicSat, 2007, pp. 207-211). The authors wish to thank Eveline Feteris and an anonymous referee for their helpful comments on a previous version of this paper. 


\section{One or Two Arguments?}

The legal literature usually describes the A Contrario Argument (ACA) as an ambiguous technique of justification. On the one hand, it can be used to justify the interpretation of a normative sentence that produces a norm claimed to be implicit in the sentence, although it does not correspond to its literal formulation. In this sense the ACA is used to claim that the case is regulated by the law: there is no gap in the law in relation to the case. On the other hand, it can be used to justify the interpretation that excludes from the application of the norm cases that do not correspond to theliteral formulation of the normative sentence. In this sense the ACA is used to claim that the case is not regulated by the law: there is a gap in the law in relation to the case ${ }^{1}$.

It is possible to give an example of this ambiguity considering the following legal sentence: "Underprivileged citizens are permitted to apply for State benefit”. Now, are underprivileged stateless persons permitted to apply for the same benefit? Two different answers can be justified by means of the ACA. The first is: according to the law, only underprivileged citizens are permitted to apply for State benefit, so stateless persons are not. The second is: the law does not regulate the position of underprivileged stateless persons in this respect.

In this paper, in order to clarify the ambiguous character of the argument, we start by considering two uses of the ACA related to the distinction between strong and weak pragmatic negation. Then we propose an inferential analysis of these two uses along the lines of scorekeeping practice as described by Robert Brandom; in so doing, we characterize such uses in terms of the normative statuses assumed by the speakers in the context of an exchange of reasons. On the basis of this analysis, we claim that a proper use of the ACA depends on some underlying ontological assumptions and some resulting incompatibility relations that are implicit in the different uses made of the argument. We conclude that the ACA in the form of a strong pragmatic negation is justified if and only if there is a relevant incompatibility between the regulated subject and the present case.

However, in general, our aim is not to justify one use of the argument over another, but to clarify the pragmatic structure of the ways it is used, looking at how the relevant properties and entities enter into the argumentative practice of lawyers and judges. What is at stake is not only a more rigorous use of the argument, but also a better understanding of what the argument depends on.

\footnotetext{
${ }^{1}$ See, among others, Guastini (1998, pp. 265-267, 338-341); cf. García (2001). In relation to the first use of the argument, it might be claimed that the ACA does not properly justify the statement "there is no gap in the law". It justifies the filling of the gap created by a literal interpretation of the normative sentence. For the purposes of this paper, however, such a consideration is not relevant.
} 


\section{Strong and weak pragmatic negation}

The A Contrario argument is also traditionally called the A Silentio argument (cf. Jansen 2003b, p. 44 ff.). This argumentative technique is concerned with what a text does not say, not with what it says. It aims to discover what the silence of the law means for the legal regulation of relevant cases. In fact, the ACA is a practical inference we often use in our everyday life. In particular, it is used when silence seems to signify, for what is not said by someone's sentences, the contrary of what is said. From the normative sentence "No smoking in public areas" we usually infer that smoking is allowed at home; from the normative sentence "Driving is permitted at 18" we infer that driving is not permitted for those who are under 18; and so on.

A schematic description of the standard use of this inference seems to be the following (where ' $p$ ' and ' $r$ ' stand for propositional contents and ' $P$ ' is the deontic operator for permission ${ }^{2}$ ):

\section{If $p$ then $P q$}

If $r$ then $\sim P q$.

It is easy to show that this use is logically incorrect. First, a different or a further premise is necessary to draw the conclusion: a premise excluding other cases from the regulation stated by the legal sentence. In particular, if the conditional is intended as a material implication, the inference is an instance of the fallacy called "denying the antecedent” (cf., Henket 1992, Kaptein 1993 and 2005, Jansen 2003a). To avoid the fallacy, one should point out that there are no other legal grounds on which the consequence should follow. Secondly, the ACA is a de dicto argument, rather than a de re argument: it concerns what is (not) said by a normative sentence, rather than what is the case as a matter of fact ${ }^{3}$. A description of a logically correct use of it could be the following:

(1) Normative sentence $S$ states "if $p$ then $P q$ "

(2) "If $p$ then $P q$ " means iff $p$ then $\mathrm{Pq}$

(3) If $\sim p$ then $\sim P q$.

Now, where does premise (2) come from? It is normally the conclusion of other inferences, whose premises are legal norms or

\footnotetext{
${ }^{2}$ But note that we sketch a general description of the ACA, not a particular one applying solely to permissions. The same ambiguity, in fact, holds for duties, permissions and other deontic specifications.

${ }^{3}$ This use of de dicto and de re specifications is somewhat different from the standard use in modal logic. Cf. Carcaterra (1994, p. 180 ff.). On de dicto and de re modalities in deontic logic, see Rossetti (1999).
} 
practical principles of communication ${ }^{4}$. In the first case, such premises are contingent: they depend on the legal system the argument is referring to, namely on the interpretation of the legal sentences excluding the existence of further legal grounds on which the consequence should follow. Here, what justifies the inference to (3) is the particular legal context of sentence $S$ (i.e., sentences $S_{1}, S_{2}, S_{3} \ldots S_{\mathrm{n}}$, and their interpretations). In the second case, such premises are not contingent: they depend on general communicative constraints such as the cooperative principle and the conversational maxims described by Grice. According to the Gricean picture (Grice 1975, p. 45), in particular, the author of $S$ is assumed to make a contribution to the communication that is adequately but not overly informative (quantity maxim). The utterance "Nigel has 14 children" commonly implicates "Nigel has only 14 children", even though it would be compatible with Nigel's having 20 children (Levinson 1983, p. 106). If the author of $S$ is assumed to observe the conversational maxim of quantity, therefore, the legal sentence "Underprivileged citizens are permitted to apply for State benefit" seems to state that only underprivileged citizens are permitted to apply for such a benefit. Here, it is the general context of communication that justifies the interpretation of $S$ as expressing a biconditional ${ }^{5}$. Regardless of being particular or general, however, the argument warrants the lawyer or the judge to draw the same conclusion: normative sentence $S$ states that iff $p$ then $P q$, therefore if $\sim p$ then $\sim P q$.

But one may challenge such a use, claiming that the ACA might justify a different interpretation of sentence $S$, namely the interpretation that excludes from the application of the norm cases that do not correspond to its literal formulation ${ }^{6}$. In this sense, "if $p$ then $P q$ " is taken to mean that if $p$ then $P q$ (and nothing else). If $\sim p$ is the case, therefore, the conclusion will be that it is not determined whether $q$ is permitted, because the circumstance is not regulated by the interpreted legal sentence. This different use of the argument could be described as follows:

(1) Normative sentence $S$ states "if $p$ then $P q$ "

(2') "If $p$ then $P q$ " means if $p$ then $P q$

$\left(3^{\prime}\right) \sim(\text { if } \sim p \text { then } P q)^{7}$.

So, assuming that $r$ is $\sim p$, the two uses of the argument bring to the following normative conclusions:

\footnotetext{
${ }^{4}$ Cf. Carcaterra (1994, pp. 222-230).

${ }^{5}$ However, if the author of $S$ is assumed to be flouting the quantity maxim, then the addressee is justified in making a different type of implicature, interpreting $S$ as expressing not a biconditional but a material conditional (or another form of implication). The addressee's assumption as to whether or not the legislator is observing or flouting the maxim of quantity depends on other contextual constraints which are not captured by the cooperative principle as described by Grice.

${ }^{6}$ Two types of A Contrario reasoning are also distinguished in Jansen (2003a) and (2003b).

${ }^{7}$ From a logical point of view, since it is not determined whether $q$ is permitted, to ( $\left.3^{\prime}\right)$ one should add ( $\left.3^{\prime \prime}\right)$, i.e., $\sim$ (if $\sim p$ then $\sim P q$ ).
} 
(3) If $r$ then $\sim P q$,

$\left(3^{\prime}\right) \sim($ if $r$ then $P q$ ).

On the one hand, (3) and (3') might seem to be logically equivalent and to have the same semantic content ${ }^{8}$. On the other, the pragmatic content of (3) and (3') is quite different. With conclusion (3), the ACA justifies the claim that $r$ is regulated by the law. In this case, the regulation of $r$ (i.e., $\sim P q$ ) will be opposite to the regulation of $p$ (i.e., $P q$ ). With conclusion ( $\left.3^{\prime}\right)$, the ACA justifies the claim that $r$ is not regulated by the law. There is a gap in the law, which could be filled by means of analogy.

To summarize, the ACA is an interpretive argument (see Alexy 1978, p. 342): it justifies the semantic content of a legal sentence in relation to the case in hand. But the semantic content of the sentence depends on the use we make of the argument in the context of our legal practice, namely on the speech acts performed by the speakers in order to justify their interpretation of the sentence.

The different speech acts performed by uttering (3) and (3') can be clarified by means of the distinction between strong pragmatic negation and weak pragmatic negation: as pointed out by contemporary nonmonotonic logic, strong negation captures the presence of implicit negative information, weak negation captures the absence of positive information ${ }^{9}$.

An utterance of (3) is an instance of strong pragmatic negation. When a judge performs (3) in a trial, he determines not only the semantic content of $S$ (i.e., if $r$ then $\sim P q$ ), but he also decides that the case is regulated by the norm so stated. When a judge performs $\left(3^{\prime}\right)$, on the contrary, he determines the semantic content of $S$ (i.e., (if $r$ then $P q$ )), but in such a way that he decides that the case is not regulated by the law. This is an instance of weak pragmatic negation, a negation that does not determine the legal regulation of the case; it determines that the case has no regulation according to the law.

\section{How argumentation is articulated from an inferential point of view}

What we have observed so far about the ACA suggests a way of overcoming the standard description of the argument, adopting a different style of analysis in order to clarify its ambiguous character. The different uses of the argument and their justification depend on some pragmatic conditions governing the interaction of the speakers in a legal context. In this sense, it is useful to consider this argument as a form of

\footnotetext{
${ }^{8}$ They are not logically equivalent if one assumes a verifunctional point of view; cf. von Wright (1959).

${ }^{9}$ The notion of strong negation was first introduced by David Nelson (see Nelson 1949). The distinction between strong and weak negation has been used, in particular, by von Wright (1959). (Cf., Mazzarese 2000, p. 115.)
} 
pragmatic interaction, which aims at determining and justifying what a legal sentence means, or does not mean, for the case in hand.

Robert Brandom has recently set out a theoretical framework permitting an analysis of this kind (cf., Brandom 1994, 2000, 2002, 2006). This framework is based on an inferentialist theory of intentionality and meaning, which explains the semantic content of a sentence in a genuine pragmatic way. In Brandom's picture, the conceptual content of a sentence is fixed by its inferential role as a premise or conclusion within an exchange of reasons. The rules governing an exchange of reasons are not determined a priori: their determination is a result of the exchange of reasons. And a genuine pragmatic explanation of inferential roles is possible if we consider the steps of the argumentation, i.e., the speech acts it is composed of, moving from the normative attitudes of the speakers. From the inferentialist point of view, to be a participant within an argumentative practice is to be responsible for the claims one makes. And to be responsible is to be taken as responsible by the other participants within the practice. In the context of legal argumentation, for example, to take another's utterance as a claim about the facts, or as a prescription drawn from a legal sentence, is to attribute inferential commitments and entitlements to the speaker: the duty to accept the consequences one is committed to, and the authority to claim the consequences one is entitled to ${ }^{10}$.

By virtue of this theoretical approach, the meaning of a sentence, that is the set of the correct inferences it can be involved in, is instituted by the practice consisting in keeping score of discursive duties (commitments) and authorities (entitlements) of the participants within the practice. Furthermore, the use of a standard set of inferences, such as the ACA, and the legal conclusions it justifies, depends on the normative attitudes of the speakers.

On the basis of considerations such as these, Brandom identifies three fundamental structures of commitment and entitlement that explain, from a pragmatic point of view, how argumentation is inferentially articulated (Brandom 1994, pp. 159-160; Brandom 2002, pp. 7-8).

(1) Commitment-preserving relations, which explain our standard deductive inferences. For example, since a legal sentence states that underprivileged citizens are permitted to apply for State benefit, anyone who is committed to the claim that Theodore is an underprivileged citizen is also committed to the claim that Theodore is permitted to apply for State benefit. This kind of

\footnotetext{
10 "Saying or thinking that things are thus-and-so is undertaking a distinctive kind of inferentially articulated commitment: putting it forward as a fit premise for further inferences, that is, authorizing its use as such a premise, and undertaking responsibility to entitle oneself to that commitment, to vindicate one's authority, under suitable circumstances, paradigmatically exhibiting it as the conclusion of an inference from other such commitments to which one is or can become entitled" (Brandom 2000, p. $11)$.
} 
relation can be schematized as follows: if one is committed to $p$, then he is committed to $q$.

(2) Entitlement-preserving relations, which explain our inductive (or abductive) inferences. For instance, since the legal position of stateless persons is normally not regulated by the State law, anyone who is entitled to the claim that Anastasia is an underprivileged stateless person is prima facie entitled to the claim that the law does not state whether Anastasia is permitted to apply for State benefit. This kind of relation can be schematized as follows: if one is entitled to $p$, then he is prima facie entitled to $q^{11}$.

(3) Incompatibility relations, which explain our modal inferences ${ }^{12}$. Two claims are incompatible if commitment to the one precludes entitlement to the other. For instance, to the extent that being a stateless person is incompatible with being a citizen, anyone who is committed to the claim that Anastasia is an underprivileged stateless person is not entitled to the claim that she is permitted to apply for State benefit according to the law. This kind of relation can be schematized as follows: if one is committed to $p$, then he is not entitled to $q^{13}$.

To clarify whether the conclusion of an ACA instantiates a strong or a weak pragmatic negation, we should analyze which normative attitudes the speakers undertake and attribute using this argumentative technique. In particular, we shall try to answer the following question: what kind of inferential relation leads to conclusion (3) and what kind to (3')? A commitment-preserving, an entitlement-preserving, or an incompatibility relation?

In order to answer this question, we propose in the next section an example of an exchange of reasons within legal argumentation, focusing on the different uses of the ACA considered above.

\footnotetext{
${ }^{11}$ Note that the letters 'p' and 'q' do not refer to the same content of the previous and next case; they just provide a schema of the relations.

${ }^{12}$ Cf. Brandom (2002, p. 8). Brandom (2006, Lecture 5) points out that incompatibility is a modal notion which makes explicit some important relations between properties: for instance, 'Pedro is a donkey' entails 'Pedro is a mammal', for everything incompatible with Pedro's being a mammal (e.g., Pedro's being an invertebrate, an electronic apparatus, a prime number) is incompatible with Pedro's being a donkey. In modal terms, if Pedro is a donkey it is not possible that Pedro is not a mammal: if the first property obtains, the second necessarily does. These incompatibility relations are not formal but material relations, that is, in Brandom's and Sellars's vocabulary, nonlogical relations; see Brandom (1994, p. 160) and Sellars (1953).

13 Note that these relations can be considered from both an intrapersonal and interpersonal point of view (see Brandom 1994, pp. 169-170). However, we believe that only the latter is relevant in the context of legal argumentation.
} 


\section{The A Contrario argument in the exchange of reasons}

Here we sketch a pragmatic interaction between lawyer $L$ and lawyer $M$ within an exchange of reasons concerning Anastasia's application for State benefit ${ }^{14}$. As we said, the structure of the interaction attributing commitments and entitlements is described by Brandom through a deontic scorekeeping model of semantic determination. Competent practitioners keep track of their own and each other's linguistic actions; they "keep score" of commitments and entitlements by attributing those deontic statuses to others and undertaking them themselves. The score is fixed from the point of view of each of the participants, and not from outside the practice. In our example, each speaker uses the ACA but thereby justifies a different interpretation of the same legal sentence, drawing from it a different conclusion. Through the linguistic interaction between $L$ and $M$, it is also possible to make explicit the pragmatic structure of these different uses of the argument at stake.

At the beginning of the exchange of reasons, imagine that lawyer $L$ performs the following speech act:

(L1) Since the law states "Underprivileged citizens are permitted to apply for State benefit”, then according to the law only citizens are permitted to apply for State benefit, and Anastasia is not, because she is a stateless person.

(L1) is an example of ACA application whose conclusion instantiates a strong pragmatic negation. Through speech act (L1), $L$ undertakes in particular the following inferential commitments (c) from the point of view of $M$ :

(c1) the law states "Underprivileged citizens are permitted to apply for State benefit";

(c2) Anastasia is a stateless person;

(c3) only citizens are permitted to apply for State benefit;

(c4) Anastasia is not permitted to apply for State benefit.

In countering $L, M$ might say:

(M1) Since the law states "Underprivileged citizens are permitted to apply for State benefit" and the law does not regulate the position of foreigners and stateless persons in this respect, then the position of Anastasia is not regulated by the law in this respect because she is a stateless person.

(M1) is an example of ACA application whose conclusion instantiates a weak pragmatic negation. Performing (M1), in an inferentialist picture, $M$ attributes two entitlements (e) to $L$ :

\footnotetext{
${ }^{14}$ For a different and more detailed example, see Canale and Tuzet (2005).
} 
(e1) the law states "Underprivileged citizens are permitted to apply for State benefit";

(e2) Anastasia is a stateless person.

This means that $L$ assumes the authority to perform (c1) and (c2), because $M$ treats such commitments as fulfilled assuming them himself. In other words, these claims of $L$ are justified from the point of view of $M$ : they are taken to be true by $L$ and $M$ (therefore they are not a matter of discussion within this exchange of reasons). But, from the point of view of $L, M$ undertakes two further commitments which are in conflict with (c3) and (c4):

(c5) the law does not regulate the position of foreigners and stateless persons in this respect;

(c6) the legal sentence "Underprivileged citizens are permitted to apply for State benefit” does not regulate Anastasia's position ${ }^{15}$.

Because of this conflict, $L$ and $M$ are requested to give further reasons in order to justify their different conclusions. $L$ might add:

(L2) Since stateless persons are not citizens, then Anastasia is not permitted to apply for State benefit.

Performing (L2), L undertakes a new commitment within the argumentative practice:

(c7) stateless persons are not citizens.

This is an important step in the argumentation of $L$, because it shows that the inference to (c4) has, from his point of view, the structure of the incompatibility relation described by Brandom. On the basis of (c7), the property of being a stateless person is claimed to be incompatible with the property of being a citizen. Those who have the former cannot have the latter and the other way round. But if being a stateless person is incompatible (in Brandom's sense) with being a citizen, it follows that anyone who is committed to the claim that Anastasia is a stateless person is not entitled to the claim that she is permitted to apply for State benefit. Then the legal sentence "Underprivileged citizens are permitted to apply for State benefit" regulates the case through a norm which does not correspond to the literal formulation of the sentence, but which is implicit in it by virtue of the incompatibility relation between the property of being a stateless person and the property of being a citizen. From the point of view of L, therefore, if $\mathrm{M}$ is committed to the claim that Anastasia is a stateless

${ }^{15}$ The incompatibility between the two sets of commitments is clear if we stress that, according to (c3), only citizens are permitted to apply for State benefit. 
person, he cannot be entitled to (c5) and (c6), i.e., to the conclusion that the legal sentence does not regulate Anastasia's position. Since Anastasia is a stateless person and the benefit at stake is reserved for citizens, the law regulates the case and Anastasia is not permitted to apply for it.

We can thus observe that a strong negation instance is the pragmatic consequence of an incompatibility relation: if the inference is based on an incompatibility relation, such as the inference to (c4), the ACA leads to a strong negation instance ${ }^{16}$.

But imagine that $M$, at this point of the argumentation, performs a further speech act:

(M2) Since being a stateless person implies prima facie not being subject to the State law, and also to sentence "Underprivileged citizens are permitted to apply for State benefit", then this sentence does not regulate Anastasia's position.

The new relevant commitment undertaken by $M$ is the following:

(c8) being a stateless person implies prima facie not being subject to the State law.

This new commitment makes explicit the pragmatic structure of the ACA whose conclusion is a weak negation instance. In (M2) the inference has the structure of an entitlement-preserving relation. If one is entitled to the claim that citizens are permitted to apply for State benefit, one is also prima facie entitled to the claim that such a norm applies only to citizens: now, since Anastasia is not a citizen, she seems not to be subject to the State law. But, what does "entitled prima facie" mean here? The conclusion of $M$ is not a necessary one, i.e., it does not result from a deductive relation (a commitment-preserving relation, using Brandom's vocabulary). It is a hypothetical claim, which produces two different pragmatic consequences: on the one hand, $M$ claims that the normative sentence does not regulate Anastasia's position; on the other, he claims that there could be another norm regulating the case within the considered legal system. Using this version of the ACA, therefore, $M$ claims that there is a gap in the law, but he also provides the possibility of filling such a gap by means of analogy.

In this sense, we can point out that a weak negation instance is the pragmatic conclusion of an entitlement-preserving relation: if the inference is based on an entitlement-preserving relation, such as the inference to (c6), the ACA leads to a weak negation instance.

There is one more question to be answered at the conclusion of our imaginary exchange of reasons between the two lawyers. Which

\footnotetext{
${ }^{16}$ From a logical point of view, however, one might claim that the inference to (c4) is a deductive inference, that is to say, using Brandom's terms, that the incompatibility relations are not separate from deductive relations.
} 
conclusion of the scorekeeping practice is the right one? Is it the strong negation of $L$ or the weak negation of $M$ ?

\section{Ontological assumptions and incompatibility relations: A sketch}

Generally speaking, the answer to the question of the correct use of the ACA depends on the context, i.e., the other reasons the speakers are giving and asking for within the argumentation (cf. Jansen 2003b and 2005). In any case, apart from the contextual background of the argumentation, our point is that, on the one hand, a strong use of the ACA is inferentially justified if and only if the properties qualifying the regulated subject are modally incompatible. On the other hand, a weak use of it is inferentially justified if and only if such an incompatibility does not hold ${ }^{17}$. There could be a legally relevant relation between the regulated subject and the present case; if so, there is a gap in the law to be filled by means of analogical reasoning. Considered in this form, the ACA is not an autonomous argument: it might be the first step of an argument from analogy. Thus, the "proper" use of the ACA is the strong one, but this does not imply that using it in this way is always justified.

Now, what are the ontological assumptions underlying the incompatibility relations? If we accept the existence of institutional facts (see Searle 1995 and 2006) we are committed, for logical reasons at least, to the acceptance of their constituents (i.e., institutional objects and properties). As far as the use of money is an institutional fact, for instance, a ten euro bill is an institutional object and its purchasing power is an institutional property. We are committed to the same conclusion with the somewhat vaguer notion of social fact: as far as there are social facts, there are social objects and properties ${ }^{18}$. Now, a social or institutional property may be incompatible with another social or institutional property: an entity having the former cannot exhibit the latter and the other way round ${ }^{19}$. Being a stateless person is incompatible with being a citizen, as well as being married is incompatible with being a bachelor, or being a contract is incompatible with being a command. Such an incompatibility might be found in Anastasia's case: since being a

\footnotetext{
${ }^{17}$ As we said, the ACA is a de dicto argument: it concerns what a legal sentence means for the case in hand; the different uses of ACA, however, depend on de re considerations, i.e., on how things are and the speakers believe them to be.

${ }^{18}$ Institutional facts are, in Searle's terminology, a subclass of social facts. Institutional and social facts differ from natural or brute facts because, in particular, they involve "collective intentionality" (Searle 1995, pp. 88-89). For a critical analysis of the notion of collective intentionality in Searle, see Celano (1999). See also Searle and Smith (2003) for some reservations on the notion of social objects.

19 Notice that, even though social properties are determined by norms, their incompatibility is alethic, not deontic: the question is, e.g., that one cannot be a citizen if he is a stateless person and vice versa, not that one should not be a citizen if he should be a stateless person and vice versa.
} 
stateless person is incompatible with being a citizen, one might focus on this in order to justify a strong use of the ACA.

In some cases, however, the ACA deals with natural properties of the regulated subject, not with social ones. Consider the ban on taking dogs on a streetcar ${ }^{20}$ : is it permitted to take cats? Here we are concerned with the natural property of being a certain kind of creature. Of course, the property of being a cat is incompatible with the property of being a dog: it is impossible for a creature to exhibit simultaneously both. So, if what we said is correct, one should conclude that also here a strong use of the ACA is justified, to the effect of allowing passengers to take cats on a streetcar. This conclusion might be resisted, however, if someone claims, first, that being a dog implies some other property, like being an inconvenient creature, and, second, that the relevant relation is the one involving the latter property, to the effect of justifying a weak use of the ACA and permitting an analogical extension (to cats) of such a prohibition. Likewise, in Anastasia's case, one might claim that being an underprivileged citizen entails being an underprivileged person, and that the relevant relation is the one involving this property and not the former. In this sense, a weak use of the ACA might be justified and the case regulated by a norm resulting from a subsequent argument from analogy.

So, what we said should be amended in the following way: $a$ strong use of the ACA is justified if and only if there is a relevant incompatibility between the regulated subject and the present case. In other words, the incompatibility relation between properties is a necessary but not sufficient condition of the ACA strong use: the properties at stake should be not only incompatible but also relevant for the legal regulation of the case (in the light of the ratio of the interpreted legal sentence).

To conclude, the incompatibility relation is central to both kind of cases, dealing with social and natural proprieties. Making it explicit shows how the deontic commitments and entitlements undertaken by the speakers determine which use of the ACA is correct in a given context. One should remember, in any case, that mere incompatibility is never enough: what we need is relevant incompatibility ${ }^{21}$. Providing criteria for such relevance is of course another story.

\footnotetext{
${ }^{20}$ This is an example we take from Ross (1958, p. 153).

${ }^{21}$ Note that also in the $A$ Simili Argument the notion of relevance is central: mere similarity is not enough, what we need is relevant similarity. On A Contrario reasoning and analogy cf. Kaptein (2005) and Jansen (2003a). Jansen distinguishes a classic and a modern form of A Contrario: with the former a rule is applied in a reversed way; with the latter a rule is not applied, not even analogically. There are similarities between the former and our strong pragmatic negation; the difference lies in the fact that our weak pragmatic negation leaves room for an argument from analogy.
} 


\section{References}

Alexy, R. (1978). Theorie der juristischen Argumentation. Die Theorie des rationalen Diskurses als Theorie der juristischen Begründung. Frankfurt a.M.: Suhrkamp.

Brandom, R.B. (1994). Making It Explicit. Reasoning, Representing, and Discursive Commitment. Harvard (Mass.) and London: Harvard University Press.

Brandom, R.B. (2000). Articulating Reasons. An Introduction to Inferentialism. Harvard (Mass.) and London: Harvard University Press.

Brandom, R.B. (2002). Tales of Mighty Dead. Historical Essays on the Metaphysics of Intentionality. Harvard (Mass.) and London: Harvard University Press.

Brandom, R.B. (2006). Between Saying and Doing: Towards an Analytic Pragmatism (The 2005-2006 John Locke Lectures). Manuscript.

Canale, D. and Tuzet, G. (2005). Interpretive Scorekeeping. In: P. Comanducci and R. Guastini (Eds.), Analisi e diritto 2005 (pp. 81-97). Turin: Giappichelli.

Carcaterra, G. (1994). L'argomento a contrario. In: S. Cassese, G. Carcaterra, M. D'Alberti and A. Bixio (Eds.), L'unità del diritto. Massimo Severo Giannini e la teoria del diritto (pp. 177-272). Bologna: Il Mulino.

Celano, B. (1999). Collective Intentionality, Self-referentiality, and False Beliefs: Some Issues Concerning Institutional Facts. Analyse \& Kritik 21, 237-250.

García Amado, J.A. (2001). Sobre el argumento a contrario en la aplicación del derecho. Doxa 24, 85-114.

Grice, H.P. (1975). Logic and Conversation. In: P. Cole and J.L. Morgan (Eds.), Syntax and Semantics. Vol. 3, Speech Acts (pp. 41-58). New York: Academic Press.

Guastini, R. (1998). Teoria e dogmatica delle fonti. Milano: Giuffrè.

Henket, M. (1992). On the Logical Analysis of Judicial Decisions. International Journal for the Semiotics of Law 5, 153-164.

Kaptein, H. (1993). E Contrario Arguments in Law: From Interpretation to Implicit Premisses. International Journal for the Semiotics of Law 6, 315-324.

Kaptein, H. (2005). Legal Progress Through Pragma-Dialectics? Prospects Beyond Analogy and E Contrario. Argumentation 19, 497-507.

Jansen, H. (2003a). E Contrario Reasoning and Its Legal Consequences. In: F.H. van Eemeren, J.A. Blair, C.A. Willard and A.F. Snoeck Henkemans (Eds.), Proceedings of the Fifth Conference of the International Society for the Study of Argumentation (pp. 557-559). Amsterdam: Sic Sat.

Jansen, H. (2003b). Van omgekeerde strekking. Een pragma-dialectische reconstructie van a contrario-argumentatie in het recht. Amsterdam: Thela Thesis.

Jansen, H. (2005). E Contrario Reasoning: the Dilemma of the Silent Legislator. Argumentation 19, 485-496.

Levinson, S.C. (1983). Pragmatics. Cambridge: Cambridge University Press.

Mazzarese, T. (2000). Permesso forte e permesso debole: note a margine. In: P. Comanducci and R. Guastini (Eds.), Analisi e diritto 2000 (pp. 113-131). Torino: Giappichelli.

Nelson, D. (1949). Constructible Falsity. The Journal of Symbolic Logic 14, 16-26.

Ross, A. (1958). On Law and Justice. London: Steven \& Sons Limited.

Rossetti, A. (1999). Modalità de re vs. modalità de dicto nella logica deontica. In: P. Comanducci and R. Guastini (Eds.), Analisi e diritto 1999 (pp. 165-181). Torino: Giappichelli.

Searle, J.R. (1995). The Construction of Social Reality. New York: Free Press.

Searle, J.R. (2006). Social Ontology: Some Basic Principles. Anthropological Theory 6, 12-29.

Searle, J.R. and Smith, B. (2003). The Construction of Social Reality: An Exchange. American Journal of Economics and Sociology 62, 285-309.

Sellars, W. (1953). Inference and Meaning. Mind 62, 313-338.

von Wright, G.H. (1959). On the Logic of Negation. Helsinki-Helsingfors: Societas Scientiarum Fennica. 